\title{
HOXB5 expression in oral squamous cell carcinoma
}

\author{
Renata TUCCI ${ }^{1}$, Marcia Sampaio CAMPOS ${ }^{2}$, Luciana Fasanella MATIZONKAS-ANTONIO'1, Marcelo DURAZZO ${ }^{3}$, \\ Décio dos Santos PINTO JUNIOR², Fabio Daumas NUNES ${ }^{2}$
}

\author{
1- DDS, PhD, Institute of Health Research, São Paulo, SP, Brazil. \\ 2- DDS, PhD, Department of Oral Pathology, Dental School, University of São Paulo, São Paulo, SP, Brazil. \\ 3- MD, PhD, Department of Head and Neck Surgery, Medical School, University of São Paulo, SP, Brazil.
}

Corresponding address: Dra. Renata Tucci - Instituto de Pesquisa em Saúde - INPES - Av. Indianópolis, 153 - Moema - São Paulo, SP - Brasil - $04063-000$ - Phone/Fax: +55-11-5051-2370 - e-mail: renata-tucci@uol.com.br

Received: June 9, 2009 - Modification: March 21, 2010 - Accepted: May 25, 2010

\section{ABSTRACT}

uman HOX genes encode transcription factors that act as master regulators of embryonic development. They are important in several processes such as cellular morphogenesis and differentiation. The HOXB5 gene in particular has been reported in some types of neoplasm, but not in oral cancer. Objective: The present study investigated the expression of HOXB5 in oral squamous cell carcinoma (SCC) and in non-tumoral adjacent tissues, focusing on verifying its possible role as a broad tumor-associated gene and its association with histopathological and clinical (TNM) characteristics. Material and Methods: RT-PCR was performed to amplify HOXB5 mRNA in 15 OSCCs and adjacent non-tumoral epithelium. A possible association with TNM and histopathologic data was verified by the chi-square and post-hoc t-test. Results: HOXB5 was amplified in 60\% non-tumoral epithelium and in $93.3 \%$ carcinomas. No statistically significant differences were found regarding the HOXB5 mRNA expression and TNM or histological grade. Conclusion: HOXB5 is expressed in OSCCs and its role in cancer progression should be further investigated.

Key words: Genes, homeobox. Carcinoma, squamous cell. Gene expression. RT-PCR, neoplasm staging.

\section{INTRODUCTION}

Squamous cell carcinoma (SCC) accounts to more than $90 \%$ of malignant tumors of the oral cavity and oropharynx. It is often related to considerable mortality and morbidity rates, and presents a variable etiology related to alcohol and tobacco abuse associated with genetic factors ${ }^{5,13}$. Despite considerable advances in the diagnostic and therapeutic possibilities, the prognosis of epithelial tumors in the oral cavity is still very poor ${ }^{15}$. In view of this, the literature raises the interest in studies that focus on the search of biological markers that can lead to an accurate prognosis followed by the appropriate management ${ }^{5,13,15}$. Since alterations of gene expression in normal tissues can be responsible for malignant phenotypes, the investigation of deregulated genes in cancerous tissues may provide important information regarding new markers for cancers ${ }^{14}$.

Recently, the literature has suggested that several molecular processes that underlie carcinogenesis might be involved with embryogenesis ${ }^{11}$. In this context, the homeobox genes, master regulators of morphogenesis and cell differentiation during embryogenesis, have emerged as potential candidates to be also involved with carcinogenesis ${ }^{1,9,16}$. This important family of genes codes regulatory proteins that act as transcriptional factors controlling the development of several tissues including orofacial tissue $^{1,16}$.

The HOX family plays a key role in the morphogenesis of vertebrate embryo cells, providing regional information along the main body axis and are vital to many aspects related to cellular growth and differentiation ${ }^{1,23}$. The human genome contains 39 HOX genes, which are clustered in a similar arrangement of 13 paralog groups in four different chromosomal regions denominated $\operatorname{HOX} A, B, C$, and $\mathrm{D}^{20,25,26}$.

HOX genes have been described deregulated in several cancers including leukemia, colon, skin, prostate, breast, ovary cancers, and more recently in oral cavity $7,24-26$. These studies suggest that the 
disturbance in the normal pattern of HOX gene expression links up with carcinogenesis in a variety of organs. Preliminary data from the Cancer Genome Project (Ludwig Institute, São Paulo, SP, Brazil) showed an overexpression of HOXB5 in head and neck tumors (data not published). However, until now, few HOX genes have been correlated with normal oral mucosa and oral SCC (OSCC) ${ }^{10}$.

Overall, the participation of HOX genes in oral cancer and the factors that control their expression in normal tissues and cancer remain unknown and should be further elucidated. The present study investigated the expression of HOXB5 in OSCC and in non-tumoral adjacent tissues, focusing on verifying its possible role as a broad tumor-associated gene and its association with histopathological and clinical (TNM) characteristics.

\section{MATERIAL AND METHODS}

\section{Sample collection}

Tissues $(n=15)$ were obtained from OSCC cases and adjacent non-tumoral mucosa at the Head and Neck Surgery Department, Clinics Hospital, São Paulo, Brazil, following the ethical procedures. The investigations were performed after approval by a local institutional review board (IRB) and in accordance with the Helsinki Declaration. Samples from adjacent non-tumoral mucosa presenting no histological evidence of dysplasia (data not shown) were used as control. Tumors were separated by nodal involvement $(\mathrm{N}+)$ or not (NO) after histopathological analysis. Histological mode of invasion was classified according to Anneroth's classification3. Clinical data were recorded (Figure 1) and each sample was prepared for histopathological analysis according to standard methods (H\&E staining). Histopathological information was examined based on clinical data and pathological criteria (low or high grade). Samples were frozen in liquid nitrogen and stored at $-80^{\circ} \mathrm{C}$ until the RNA extraction by the TRizol method (Invitrogen, Carlsbad, CA, USA) according to the manufacturer's instructions. To rule out the possibility of contamination with genomic DNA, the total RNA was incubated with DNase I, amplification grade (Invitrogen) at room temperature for $15 \mathrm{~min}$, followed by $10 \mathrm{~min}$ at $65^{\circ} \mathrm{C}$ with the addition of $25 \mathrm{mM}$ of EDTA. The RNA integrity of samples was evaluated based on the intensity of $28 \mathrm{~S}$ and $18 \mathrm{~S}$ rRNA bands on agarose gels.

\section{cDNA preparation}

Reverse transcription-PCR (RT-PCR) was performed in $20 \mathrm{~mL}$ of reaction mixture containing $2 \mathrm{~mL}$ of oligo (dT) and $4 \mathrm{mg}$ of total RNA at $70^{\circ} \mathrm{C}$ for $10 \mathrm{~min}$. After that, $2 \mathrm{~mL}$ of DTT, $1 \mathrm{~mL}$ of dNTPs and $4 \mathrm{~mL}$ of $5 \mathrm{x}$ buffer were incubated during $10 \mathrm{~min}$ at $25^{\circ} \mathrm{C}$, followed by $1 \mathrm{~mL}$ of Superscript II reverse transcriptase (Invitrogen) for $50 \mathrm{~min}$ at $42^{\circ} \mathrm{C}$, and a final step at $70^{\circ} \mathrm{C}$ for $15 \mathrm{~min}$.

Semi-quantitative real-time polymerase chain reaction ( $R T-P C R$ )

Specific HOXB5 primer sets were designed using GeneTool 1.0 software (BioTools Inc., Alberta, Canada). About $5 \mathrm{~mL}$ of the reversetranscribed mixture (cDNA) was used as a template for PCR, using Taq polymerase Platinum (Invitrogen) in the presence of $200 \mathrm{mM} \mathrm{HOXB5}$ specific primers ( $5^{\prime}$-TGCATCGCTATAATTCATT- $3^{\prime}$ and 5'-GCCTCGTCTATTTCGGTGA-3'). Amplification was carried out in a PT100 thermocycler (MJ Research, Watertown, MA, USA) for 35 cycles (40 $\mathrm{s}$ of denaturation at $94^{\circ} \mathrm{C}, 1 \mathrm{~min}$ of annealing at $65^{\circ} \mathrm{C}$ and $1 \mathrm{~min}$ of extension at $72^{\circ} \mathrm{C}$ ). Alternatively, conventional RT-PCR reactions for b-actin gene ( $5^{\prime}$-CCTTCCTGGGCATGGAGTCCTG-3' and 5'-GGAGCAATGATCTTGATCTTC3') were carried out for all samples and used as an endogenous control of positive amplification demonstrating the presence of mRNA in all tested samples. A negative control (absence of CDNA) was included in all RT-PCR reactions to ensure the absence of DNA contamination and false positives. The amplicons were analyzed by electrophoresis on $2 \%$ NuSieve agarose gels (FMC Bioproducts, Rockland, Manie USA), and documented using digital photographs. Semi-quantitative analyses were performed based on the quantification of ethidium bromide stained RT-PCR products and using the NIH IMAGE 1.55 program. For each sample, the intensity of bands obtained with the HOXB5 amplification was normalized with respective b-actin RT-PCR products.

\section{Statistical analysis}

After normalization using $\beta$-actin gene, the triplicate of each data point generated by semiquantitative assays was submitted to statistical analysis. The difference of the expression levels of HOXB5 in OSCC specimens and non-tumoral tissues, as well as the association among HOXB5 mRNA levels, TNM classification and histological grade were analysed by chi-square test and Fisher's test $(p<0.01)$.

\section{RESULTS}

Clinical features, pathological data and HOXB5 expression in OSCC and non-tumoral tissues are summarized in Figure 1. In detail, the majority of the studied patients were male $(10 / 15)$ representing $66.7 \%$, while 5 patients were female $(33.3 \%)$. The mean age was 58 years raging from 22 to 87 years. The preferential site of the OSCC was the tongue ( 10 cases, $66.7 \%$ ), followed by floor of mouth (4 cases, $26.7 \%$ ) and maxilla (1 case, 6.6\%). According to 


\begin{tabular}{|c|c|c|c|c|c|c|c|c|}
\hline $\begin{array}{c}\text { Patient } \\
\text { ID }\end{array}$ & Site & Gender & Race & Age & TNM & $\begin{array}{c}\text { Histologic } \\
\text { graduation }\end{array}$ & $\begin{array}{c}\text { HOXB5 in } \\
\text { normal tissue }\end{array}$ & $\begin{array}{c}\text { HOXB5 in } \\
\text { tumor }\end{array}$ \\
\hline 1 & Tongue & $\mathrm{F}$ & $\mathrm{W}$ & 56 & T1N0M0 & High grade & + & + \\
\hline 2 & Tongue & $\mathrm{F}$ & $\mathrm{W}$ & 78 & T1N0M0 & Low grade & - & + \\
\hline 3 & Floor & $\mathrm{M}$ & $\mathrm{W}$ & 50 & T4N0M0 & High grade & + & - \\
\hline 4 & Tongue & $\mathrm{F}$ & $\mathrm{W}$ & 25 & T4N0M0 & High grade & - & + \\
\hline 5 & Maxilla & $\mathrm{M}$ & $\mathrm{B}$ & 87 & T4N0M0 & Low grade & + & + \\
\hline 6 & Floor & $\mathrm{M}$ & $\mathrm{W}$ & 56 & T4N0M0 & Low grade & - & + \\
\hline 7 & Tongue & $\mathrm{F}$ & $\mathrm{W}$ & 70 & T1N2M0 & Low grade & + & + \\
\hline 8 & Tongue & $\mathrm{M}$ & $\mathrm{W}$ & 80 & T1N2M0 & Low grade & - & + \\
\hline 9 & Tongue & $\mathrm{M}$ & $\mathrm{W}$ & 56 & T2N1M0 & High grade & + & + \\
\hline 10 & Tongue & $\mathrm{F}$ & $\mathrm{W}$ & 55 & T2N2M0 & Low grade & + & + \\
\hline 11 & Tongue & $\mathrm{M}$ & $\mathrm{W}$ & 22 & T4N1M0 & Low grade & - & + \\
\hline 12 & Floor & $\mathrm{M}$ & $\mathrm{W}$ & 50 & T4N2M0 & Low grade & + & + \\
\hline 13 & Tongue & $\mathrm{M}$ & $\mathrm{W}$ & 58 & T4N2M0 & Low grade & & + \\
\hline 14 & Tongue & $\mathrm{M}$ & $\mathrm{W}$ & 67 & T4N2M0 & Low grade & & + \\
\hline 15 & Floor & $\mathrm{M}$ & $\mathrm{W}$ & 60 & T4N3M0 & High grade & + & + \\
\hline
\end{tabular}

M=Male; F=female; $W=$ white; $B=$ black

Figure 1- Clinical and histological parameters of the OSCC analyzed and the respective HOXB5 mRNA expression in OSCC and corresponding normal tissues
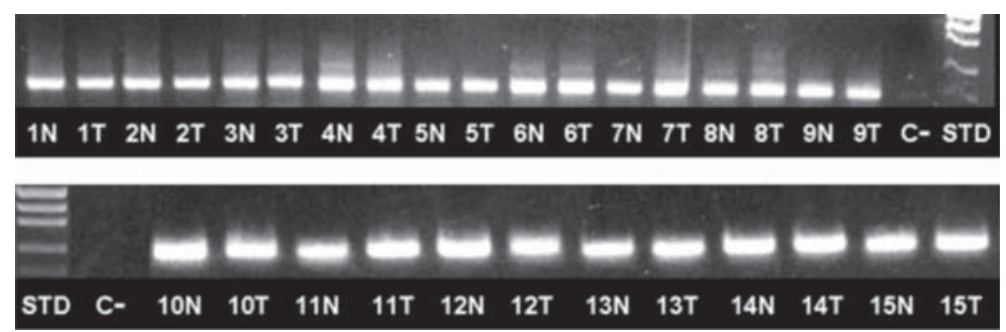

Figure 2- $\beta$-actin (housekeeping gene) mRNA expression in OSCC cases and normal tissues. Numbers represent the sample (patient); C-=Negative control (no template); STD=molecular weight standard; $\mathrm{N}=$ =non-tumoral mucosa; $\mathrm{T}=$ tumor
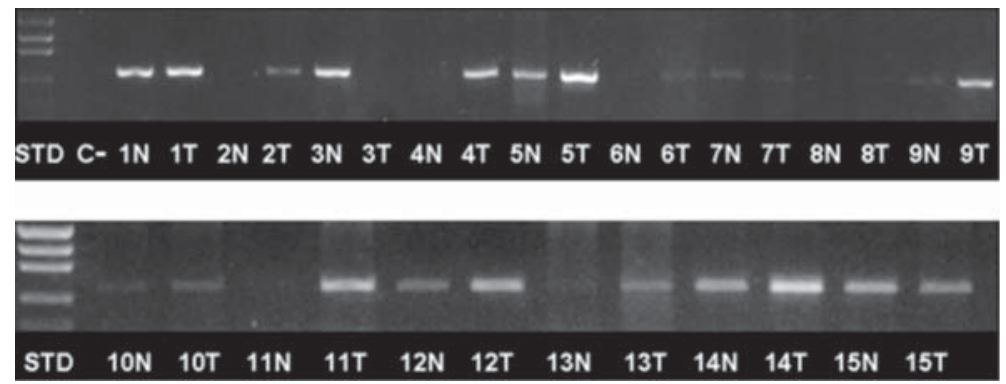

Figure 3- HOXB5 mRNA expression in OSCC cases and normal tissues. Numbers represent the sample (patient); $\mathrm{C}$-=Negative control (no template); STD=molecular weight standard; $\mathrm{N}=$ non-tumoral mucosa; $\mathrm{T}=$ tumor

the TNM clinical classification, 4 carcinomas were classified as T1 $(26.6 \%), 2$ as T2 $(13.3 \%)$, and 9 as T4 $(60.1 \%)$. Nine cases presented lymph node involvement and none had metastases (M0).

Presence and viability of cDNA was checked in all samples using an endogenous control gene (b-actin). According to these results, b-actin amplification was confirmed in all cases (Figure 2). Although, HOXB5 expression was observed in both OSCC and in nontumoral (NT) tissues, its expression was more present in OSCC. HOXB5 transcripts were found in 9/15 $(60 \%)$ of NT, and in $14 / 15(93.3 \%)$ of OSCC tissues
(Figure 3). As shown in Figure 1, in patients 2, 4, 6, 8, 11 and 13, HOXB5 expression was observed exclusively in OSCC tissues and no expression was observed in NT tissues, while only in the patient 3 the opposite was observed.

Additionally, patients 1, 5, 7, 9, 10, 12, 14 and 15 presented positive expression of HOXB5 in both sites (tumoral and NT samples). When grouping patients according to the $\mathrm{N}$ status, in the absence of nodal involvement (NO), 2/6 (33.3\%) patients showed HOXB5 expression in both sites $(+/+), 3 / 6$ (50\%) patients showed HOXB5 expression only in tumor 
$(-/+)$, while $1 / 6$ patient presented HOXB5 expression exclusively in normal site (+/-). On the other hand, when nodal involvement $(\mathrm{N}+)$ was present, 5/9 (55.5\%) patients showed HOXB5 expression in both sites $(+/+), 3 / 9(33.3 \%)$ presented HOXB5 expression exclusively in tumoral sites $(-/+)$, and no patient showed HOXB5 expression only in normal site (+/-).

After histopathological analysis, 10 cases were classified as low grade (66.7\%) and 5 cases classified as high grade (33.3\%). HOXB5 expression was observed in $10 / 10$ cases classified as low grade $(100 \%)$ and in $4 / 5$ cases classified as high grade $(80 \%)$. No significant association was observed between HOXB5 expression and clinical features (TNM) and histological grade of the patients studied $(P=1.00$, chi-square test).

\section{DISCUSSION}

The expression of HOXB5 was analyzed in OSCC samples and compared to NT adjacent tissues in order to obtain information about its involvement in oral carcinogenesis. Also, this study tried to verify a possible association of the HOXB5 expression with TNM, clinical data and histological grade. According to the results, HOXB5 was expressed in most $(93.3 \%)$ of the OSCC analyzed, independently of the TNM status. However, when considering N status, a regulation based on losses and gains of HOXB5 expression in normal sites versus tumoral sites could be verified. Association with other parameters was not statistically significant.

Previous studies showed changes in the expression of some HOX genes in several tumours including oesophagus, leukemia, stomach and colon, but until now, this point was poorly addressed in OSCC ${ }^{26}$. Recently, a study described the presence of HOX genes in oral dysplasias, OSCC and normal mucosa suggesting that misexpressions of particular HOX genes are implicated in the development of oral dysplasia and OSCC $^{10}$. Moreover, another recent study using human minor salivary gland showed that HOXB13 transcripts were differently expressed in normal mucous and serous acini, concluding that it may possibly reflect a different role of the HOX genes in salivary gland carcinogenesis ${ }^{6}$.

Currently, is common to assume an important relationship between carcinogenesis and embryogenesis ${ }^{1,9}$, suggesting that genes involved with development, as HOX genes, are deregulated during malignant transformation and cancer establishment $7,16,19$. Moreover, homeobox genes are reported as useful tools to identify undifferentiated tumors or metastasis with unknown origin ${ }^{19}$.

Among the HOX genes, HOXB5 was found overexpressed in head and neck SSC (Ludwig Institute, São Paulo, Brazil, data not shown). Furthermore,
HOXB5 is located at 17 p21.3 chromosome, a region recently reported with high percentage of loss of heterozygosis in head and neck SCC${ }^{2}$ which suggests that this gene should be better investigated in OSCC. Using RT-PCR, HOXB5 transcripts were frequently amplified in tumoral and non-tumoral samples. Although HOXB5 expression was more present in OSCC samples (93.3\%) than in non-tumoral tissues $(60 \%)$, this difference was not statistically significant $(P=0.03$, chi-square test), and could be considered as a "borderline significance". A larger number of standardized samples, in a future quantitative investigation, would help clarifying this issue.

Regarding the parameters included in this study, the cervical lymph node metastasis was used since it is a poor prognostic indicator in patients with OSCCs ${ }^{12}$. The results showed that, when grouping patients according to the presence or not of nodal involvement, $50 \%$ of the patients with NO showed gain of HOXB5 in tumor site represented by the relation $-/+$ (non tumoral-tissue/tumor). Interestingly, 55\% of the patients with nodal involvement $(\mathrm{N}+)$ showed expression in both sites, but none of the patients presented HOXB5 expression only in non-tumoral tissues. Taken together, these data suggest a trend that a loss of HOXB5 expression in normal sites and a gain of HOXB5 in tumor sites can be related to nodal involvement and poor prognosis. However, these results were not statistically significant. A tumor that metastasizes to the regional nodes can be considered aggressive and, because of this biologic characteristic, could cause a propensity to recur after treatment. If the latter concept is correct, a relationship between neck nodes and recurrence at the primary site would seem logical. Therefore, it would be interesting to verify if HOXB5 expression in epithelium adjacent to OSCC is related to recurrence or incidence of second primary tumors. Unfortunately, all patients studied here were treated in less than 1 year. It would also be interesting to see the epithelial expression of HOXB5 in different areas of the mouth, and related to the diverse patterns of keratinization, but this was not the goal of this study. Also, the inclusion of normal oral tissue would be ethically questionable.

It is widely accepted that the processes of normal embryogenesis and neoplasia share many pathways, and that tumor development is an aberrant form of organogenesis ${ }^{1,21}$. Typically, those homeobox genes that are upregulated or "gained" expression in carcinoma normally show expression patterns that are restricted to undifferentiated or proliferative cells. Conversely, homeobox genes that are downregulated or "lost" in carcinoma are normally expressed in fully differentiated tissues. These considerations can justify the variable pattern of HOXB5 expression found in this study, except the absence of amplification in both non-tumoral and tumoral samples. This issue was 
not considered a technical artifact since mRNA was of optimal quality, and experiments were extensively optimized and performed in triplicate. Since it is well known that homeobox are regulated by co-factors ${ }^{8,18}$, it is possible that in those cases where HOXB5 was not amplified, these co-factors could be overexpressed.

Finally, no statistically significant association was observed among the HOXB5 expression profile, clinical features (TNM) and histological grade of the patients studied. Perhaps a larger number of patients would help establishing a correlation. The absence of standardization of the patients might also be responsible for the great difficult to associate the data generated by RT-PCR assay to TNM or histological grade classifications. In this context, many authors report a strict correlation between these parameters and the prognosis of OSCC ${ }^{3,17}$. On the other hand, while some authors consider the TNM clinical classification as one of the best indicators of the prognosis of $\mathrm{SCC}^{22}$, others consider it limited ${ }^{4}$. In the same way, histological grading usually does not reflect the biological behavior of the $\mathrm{SCC}^{4,22}$.

\section{CONCLUSION}

The results presented here support that expression of HOX genes is associated with OSCC. Since over $90 \%$ of OSCC samples presented HOXB5 expression versus $60 \%$ of NT tissues, it can be suggested that HOXB5 may be related to the malignant phenotypes. In this case, a future quantitative analysis may be suitable to verify if the HOXB5 gene is overexpressed in OSCC tissues, thus making our suggestion stronger. Presence of HOXB5 only in OSCC or only in NT confirms the hypothesis that homeobox genes are probably regulated by losses and gains. Unfortunately, no significant association was observed among the HOXB5 expression, clinical features (TNM) and histological grade of the patients studied. Since several parameters were analyzed in the present study, future investigations should include a larger number of standardized samples.

\section{ACKNOWLEDGMENTS}

The authors thank FAPESP (Process 2001/136446 ) and CAPES (PhD grants for Dr. Renata Tucci) for financial support.

\section{REFERENCES}

1- Abate-Shen C. Deregulated homeobox gene expression in cancer: cause or consequence? Nat Rev Cancer. 2002;2:777-85.

2- Abou-Elhamd KE, Habib TN, Moussa AE, Badawy BS. The role of genetic susceptibility in head and neck squamous cell carcinoma. Eur Arch Otorhinolaryngol. 2008;265:217-22.

3- Anneroth G, Batsakis J, Luna M. Review of the literature and a recommended system of malignancy grading in oral squamous cell carcinomas. Scand J Dent Res. 1987;95:229-49.
4- Bankfalvi A, Piffko J. Prognostic and predictive factors in oral cancer: the role of the invasive tumour front. J Oral Pathol Med. 2000;29:291-8.

5- Bettendorf O, Piffkò J, Bànkfalvi A. Prognostic and predictive factors in oral squamous cell cancer: important tools for planning individual therapy? Oral Oncol. 2004;40:110-9.

6- Cazal C, Sobral AP, Almeida FC, Graças Silva-Valenzuela M, Durazzo MD, Nunes FD. The homeobox HOXB13 is expressed in human minor salivary gland. Oral Dis. 2006;12:424-7.

7- Chen KN, Gu ZD, Ke Y, Li JY, Shi XT, Xu GW. Expression of 11 HOX genes is deregulated in esophageal squamous cell carcinoma. Clin Cancer Res. 2005;11:1044-9.

8- Crijns AP, Graeff P, Geerts D, Ten Hoor KA, Hollema H, Van Der Sluis $T$, et al. MEIS and PBX homeobox proteins in ovarian cancer. Eur J Cancer. 2007;43:2495-505.

9- Gehring WJ, Hiromi Y. Homeotic genes and the homeobox. Annu Rev Genet. 1986;20:147-73.

10- Hassan NM, Hamada J, Murai T, Seino A, Takahashi Y, Tada M, et al. Aberrant expression of HOX genes in oral dysplasia and squamous cell carcinoma tissues. Oncol Res. 2006;16:217-24.

11- Kelleher FC, Fennelly D, Rafferty M. Common critical pathways in embryogenesis and cancer. Acta Oncol. 2006;45:375-88.

12- Leemans CR, Tiwari R, Nauta JJ, Van Der Waal I, Snow GB. Recurrence at the primary site in head and neck cancer and the significance of neck lymph node metastases as a prognostic factor. Cancer. 1994;73:187-90.

13- Massano J, Regateiro FS, Januário G, Ferreira A. Oral squamous cell carcinoma: review of prognostic and predictive factors. Oral Surg Oral Med Oral Pathol Oral Radiol Endod. 2006;102:67-76.

14- Mobasheri MB, Jahanzad I, Mohagheghi MA, Aarabi M, Farzan S, Modarressi MH. Expression of two testis-specific genes, TSGA10 and SYCP3, in different cancers regarding to their pathological features. Cancer Detect Prev. 2007;31:296-302.

15- Németh Z, Velich N, Bogdan S, Ujpál M, Szabó G, Suba ZS. The prognostic role of clinical, morphological and molecular markers in oral squamous cell tumors. Neoplasma. 2005;52:95-102.

16- Nunes FD, Almeida FC, Tucci R, Sousa SC. Homeobox genes: a molecular link between development and cancer. Braz Oral Res. 2003;17:94-8.

17- Oliver AJ, Helfrick JF, Gard D. Primary oral squamous cell carcinoma: a review of 92 cases. J Oral Maxillofac Surg. 1996;54:949-54; discussion 55.

18- Owens BM, Hawley RG. HOX and non-HOX homeobox genes in leukemic hematopoiesis. Stem Cells. 2002;20:364-79.

19- Redline RW, Hudock P, MacFee M, Patterson P. Expression of AbdB-type homeobox genes in human tumors. Lab Invest. $1994 ; 71: 663-70$

20- Ruddle FH, Bartels JL, Bentley KL, Kappen C, Murtha MT, Pendleton JW. Evolution of Hox genes. Annu Rev Genet. 1994;28:423-42.

21- Samuel S, Naora H. Homeobox gene expression in cancer: insights from developmental regulation and deregulation. Eur J Cancer. 2005;41:2428-37.

22- Silveira EJ, Godoy GP, Lins RD, Arruda Mde L, Ramos CC, Freitas Rde $A$, et al. Correlation of clinical, histological, and cytokeratin profiles of squamous cell carcinoma of the oral tongue with prognosis. Int J Surg Pathol. 2007;15:376-83.

23- Stein S, Fritsch R, Lemaire L, Kessel M. Checklist: vertebrate homeobox genes. Mech Dev. 1996;55:91-108.

24- Takahashi Y, Hamada J, Murakawa K, Takada M, Tada M, Nogami I, et al. Expression profiles of 39 HOX genes in normal human adult organs and anaplastic thyroid cancer cell lines by quantitative realtime RT-PCR system. Exp Cell Res. 2004;293:144-53.

25- Van Oostveen J, Bijl J, Raaphorst F, Walboomers J, Meijer C. The role of homeobox genes in normal hematopoiesis and hematological malignancies. Leukemia. 1999;13:1675-90.

26- Yahagi N, Kosaki R, Ito T, Mitsuhashi T, Shimada H, Tomita $M$, et al. Position-specific expression of Hox genes along the gastrointestinal tract. Congenit Anom (Kyoto). 2004;44:18-26. 